\title{
A biosemiotic conversation: Between physics and semiotics
}

\author{
Howard H. Pattee' \\ Kalevi Kull ${ }^{2}$ \\ ${ }^{1} 1611$ Cold Spring Road, Williamstown, MA 01267, USA \\ e-mail:pattee@adelphia.net \\ ${ }^{2}$ Department of Semiotics, University of Tartu; Tiigi 78, 50410 Tartu; Estonia \\ e-mail:kalevi.kull@ut.ee
}

\begin{abstract}
In this dialogue, we discuss the contrast between inexorable physical laws and the semiotic freedom of life. We agree that material and symbolic structures require complementary descriptions, as do the many hierarchical levels of their organizations. We try to clarify our concepts of laws, constraints, rules, symbols, memory, interpreters, and semiotic control. We briefly describe our different personal backgrounds that led us to a biosemiotic approach, and we speculate on the future directions of biosemiotics.
\end{abstract}

We have started this conversation standing at the base of Massachusetts' highest mountain. The forest on the top was hidden from our sight by clouds. We talked on several biosemiotic themes, which we develop further here; but where they lead us is unpredictable. That is life.

\section{The regions for life in the physical world}

$K$. The first problem we need to solve is evidently to demonstrate how the possibility of choosing one's path - a characteristic feature of all life - can be embedded into the picture of physical world which is based on inexorable physical laws. Everything in the world (at least 
that can be measured) is consistent with physical laws. Yet there is what you have characterized as open-ended evolution. ${ }^{1}$ Would you agree if we call it - equivalently - as a freedom to establish new rules?

$\boldsymbol{H}$. Yes, it would certainly include establishing new rules, but by openended I want to include any emergent structure, function or behavior that can be imagined - or perhaps even behavior that we can't imagine because of the limitations of our current brains. We can't predict what novelties evolution might produce.

$\boldsymbol{K}$. The open-ended evolution includes then two distinct properties. (1) an immense ${ }^{2}$ number of potential forms, and (2) a basic unpredictability of the paths evolution will take. These features, accordingly, apply to biological evolution and do not apply to the evolution in nonliving world.

H. The physical basis of the immense number of forms is a consequence of the immense number of linear sequences of material units that laws cannot distinguish because of their similar energy or similar stability. This is the genetic memory. Only some form of "frozen accident" or higher level selection process affects which memory sequences survive over time. Not only are the initial sequences unpredictable, but their physical structure appears to be largely arbitrary. Natural selection is also unpredictable because of its complexity and the indefinite time period over which selection continues to work.

The most obvious, and I would say the most important, similarities of genetic language and human natural, formal, and computer languages is their expression by such discrete, linear strings using only a small, materially arbitrary alphabet. It is just these properties that allow simple and reliable writing, reading, and storage in a memory

For example, Pattee 1988: 69.

With this term I would refer to Walter Elsasser (1998: 49ff) who has emphasized the role of immenseness in this sense as a characteristic feature of life. 
that is lawfully undetermined, and that allows practically unlimited information capacity.

$\boldsymbol{K}$. The consistency with physical laws means that everything is dependent on the laws - none of biological or mental processes is inconsistent with any physical law. However, as you say, this does not mean that everything is determined by the laws. ${ }^{3}$ The "regions of indeterminacy" are supposedly those in which life can establish itself and evolve. Is it possible to describe these regions of indeterminacy and how they arise?

$\boldsymbol{H}$. The inexorable character of physical law is often misunderstood to imply determinism. This is not the case. There are innumerable structures in the universe that physical laws do not determine. It is also important to understand why lawfully indeterminate does not mean physically indistinguishable.

Since all the basic laws of physics are expressed in terms of energy, systems with two or more states with the same energy are lawfully indeterminate. However, in many cases we can distinguish these states by measurements of their initial conditions. These law-equivalent states are often called degeneracies or symmetries.

A common example is chirality, or left and right handedness. Chemically, amino acids and proteins can be left or right handed, and they cannot be distinguished by the laws that they both obey. Nevertheless, most types of biochemicals in living organisms must stick with one or the other.

This is like our driving on one side of the road. Either side would work just as well as the other, but we have to choose one for traffic to function efficiently. Such symmetry-breaking events that persist for structural, functional, or selective reasons are appropriately called "frozen accidents".

The most important energy-degenerate structures for life and language are the linear strings of discrete units like nucleic acids and

3 Pattee 2008: 151. 


\section{Howard H. Pattee, Kalevi Kull}

the strings of symbols like the words on this page that form a memory. It is just because of the immense numbers of these energy-indeterminate but structurally distinguishable strings of symbols that their information storage capacity is open-ended. These distinguishable sequences and the information they contain are not determined or restricted by natural laws; but their relative permanence is the result of frozen accidents, and natural or cultural selection in specific environments. Most linguistic conventions are probably frozen accidents. It is possible that the genetic code and consequently life itself began as a broken symmetry that became a frozen accident.

$K$. Isn't redundancy a more precise term than degeneracy in these cases?

$\boldsymbol{H}$. The word "degeneracy" is physical jargon that is not equivalent to "redundancy". More precisely, linear copolymers are "near-degeneracies" meaning that their stabilities or lifetimes are nearly the same as long as they remain linear and isolated. So far this is just a "meaningless" physical necessity that allows an unlimited variety of sequences.

Degeneracy is more closely related to what physicists call a symmetry where any change of sequence order does not change the lawbased description. Degeneracy has nothing to do yet with semiotics or potential functions where "redundancy" may have meaning.

K. Still, it seems to me, we have not yet entirely explained how the living systems - or sign processes - escape from the determinism of the physical laws. Because the existence of energetically degenerate states yet does not mean that what will happen will not be determined by the initial conditions - as for instance in case of a growth of a nucleotide strain, the choice of the next nucleotide is not determined by the previous nucleotide, however it can be determined by a movement of the nucleotides around (e.g., the one that will reach the endpoint of the strain first would stay there). 
In other words, in order to explain the appearance of semiotic freedom ${ }^{4}$ the existence of law-equivalent events is necessary, but this cannot be achieved on solely molecular level. It is necessary to demonstrate the emergence of non-determined regulation by boundary conditions. Otherwise the freedom is basically illusionary, as for instance Daniel Dennett would claim.

$\boldsymbol{H}$. The concept of absolute determinism as envisioned by Laplace and philosophers like Dennett, has turned out in physics to be an unsupportable and unproductive way of thinking. Determinism is an untestable metaphysical concept. First of all, measurement processes are irreversible and therefore dissipative and subject to error, so determinism is not empirically verifiable. All the fundamental laws are consistent only with a probabilistic universe. We have enough "freedom" just because of the undeterminable or equivalent probabilities of many structures, like polymer sequences.

There is also plenty of freedom just at this molecular level to allow brains to make choices because all brain function is dependent on the molecular level. As Arthur Eddington (1929: 260) noted long ago: "There is nothing to prevent the assemblage of atoms constituting a brain from being of itself a thinking object [with "free will"] in virtue of that nature which physics leaves undetermined and undeterminable".

$K$. You have used the term constraint as a central notion in your writings. How should constraint be defined?

H. In physics a constraint is a local structure that limits the motions of otherwise "free" particles that are governed only by the laws of motion. However, the concept of constraint is also used to describe levels of hierarchical organizations. Generally speaking, each higher level requires a constraint that is described by fewer observables than the

\footnotetext{
4 The concept of semiotic freedom is central to Jesper Hoffmeyer's writings (for example, Hoffmeyer 2008).
} 
lower level description. More precisely, a constraint is an alternative simplified description of structures that are not usefully described by the behavior at a more detailed lower level.

A simple example is a closed box that limits the detailed motions of the gas molecules inside. The box itself is also made of molecules, but they are constrained by chemical bonds to form a solid structure. So we simplify the description of the box by describing only its geometric boundaries, and we ignore the detailed molecular structure of the box itself. Such constraints are also called "boundary conditions".

A more complicated example is an internal combustion engine. The entire engine is made of molecules, but they are so rigidly constrained as solid parts that we can usefully describe the engine's motion by just one rotational degree of freedom. Engines constrain the gas molecules in the cylinders so that, by coupling to several higher levels of fixed and moving constraints, it does useful work.

A very complicated example is the computer that at the lowest level simply constrains the flow of electrons. At a higher design level these constraints are described as circuits, memories and gates. However, when we use a computer we ignore this hardware level of constraint because it is more practical to control its behavior at a higher level of symbolic constraint we call a code or program. A reasonably complete understanding of a modern computer requires different descriptions and languages for at least six levels of constraints.

Biosemiotics covers even more levels of constraints, from the chemical bonds that constrain gene sequences, enzyme dynamics, and cell membranes, to the matter-symbol transition of the structural genes and the epigenetic controls of development, and finally to the nervous system architecture and the brain. Consequently our biosemiotic models require many different levels of descriptions. Failure to recognize that these different levels of descriptions are necessary and complementary often causes useless arguments over which is the "best" description.

By contrast with the computer, the organism itself must develop almost all of its higher level constraint structures under the supervision of the genetic description. The genetic constraints harness the 
self-organizing physical laws with great efficiency, like protein folding and the self-assembly of components, all of which follow energy dependent laws. In other words, a relatively few genetic constraints control a large number of energy-based physical actions and constructions. As we now are learning from gene sequencing, the simple structural genes are only a small fraction of the genome. Most of the genome is made up of control sequences that are coordinated by extremely complex linkages. How this coordination arises is the key problem of evolution and development (Pattee 1971a).

$K$. Thus, there are constraints both in the non-living and the living world. But aren't these constraints radically different? As we can observe, the constraints in the living world are, (a) fundamentally individual, due to the individuality of each organism, and (b) mutual or reciprocal, due to the communication processes that occur between any living beings, between the cells, and between the organisms. As a result of the individual and mutual constraints, the relations become established between the living systems - the relations (I would see these also as rules, or codes) that might be unpredictable from the physical laws.

$\boldsymbol{H}$. Yes, living and nonliving constraints are radically different for the reasons you give. Nonliving constraints are not constructed from heritable memory that persists by natural selection. Living constraints occur in individuals with a memory. Genes are the memory that define the individual. As Hippocrates recognized, your conscious individual self is memory in your brain. All your other organs can be transplanted without changing your individual awareness. The same is true of the genes at the cellular level.

$\boldsymbol{K}$. A living system can establish constraints and do work in this way. Via doing work, it can then build whichever structures, both useful and just for fun, or also in a "let's see what comes out of it" way. The work done with the help of constraints is all using physical processes, which means that no freedom from the laws, no indeterminacy is 
really required for this part of the life process. The freedom from laws (in the sense of law-equivalence, or indeterminacy), however, as it seems, is necessary in order to make choices, i.e. to behave in a way that would not be predictable by any computational means.

$\boldsymbol{H}$. To be more precise, you never have "freedom from laws" but only freedom of initial or boundary conditions. You have to make a clear distinction between laws and constraints. Laws are universal and inexorable. Nothing is free of laws. Constraints are local structures that obey laws but are not determined or predictable by laws. Memory is a special type of constraint that can alter or control the lawful course of local events. Polanyi's (1968) phrase "harnessing the laws" is apt.

It is only memory constraints that allow an organism's heritability, variation and natural selection. At the cognitive level, it is only by consulting our memory that we feel we are making choices. A sudden response to a stimulus, like a loud noise, does not feel like a choice.

$\boldsymbol{K}$. Nevertheless, we may probably think of common free behaviour also without any inclusion of law-equivalent states. For instance, if a behavioural act is a habit-based search for an object represented by its memory, driven by an organism's need and taking into account the umwelt around - it is not obvious that any law-equivalent state is required for such a behaviour.

$\boldsymbol{H}$. Exactly. It is just because it is law-equivalent that that law-based thinking is irrelevant. Semiotic expression is free of physical laws. The existence of any memory requires many law-equivalent states. In fact, the information capacity of a memory is defined in terms of the number of law-equivalent (equiprobable) states.

K. A behavioural act may result in some learning, which means a slight change of memory, and thus the behaviour will be fully individual, and also unpredictable, because the response cannot be calculated - exactly analogically to the complete function of an enzyme that also cannot be calculated. Thus, a question still is: 
whether a complex individuality is not already sufficient to provide all behaviours the organisms may have?

$\boldsymbol{H}$. Again I would say that any "complex individuality" is defined only by its memory, and therefore such memory-controlled individuals would be capable of evolving or learning many forms of behavior.

K. A particular constraint can be produced deterministically, like the shores of a river as the river is shaping them. But if there is a system of constraints, in which the constraints mutually rebuild each other, whereas the reproduction of the constraints is based on a non-exact mutual recognition, then an identity can arise, which turns out to be quite independent from microprocesses.

For instance, in a population of biparentally reproducing organisms each individual is genetically different from any other, but they recognise each other when producing offspring and thus form a species that holds itself.

This is like an ongoing communication, in which the communicants reciprocally constrain each other and thus the self-identity of the communication process is kept. Life is probably just this kind of general communication process.

In order to get life running, what is required is an inheritance mechanism, i.e. memory - the one that consumes energy in order to rebuild itself; the inheritance mechanism ${ }^{5}$ obviously has to include semiosis, because it has to find and recognise its building blocks. And the inheritance mechanism is nothing else than a general selfsupporting communication mechanism, as I just tried to describe it.

$\boldsymbol{H}$. I would agree that even the simplest reproduction requires the communication of information from parent to offspring. All multicellular development is also dependent on communication between

5 Inheritance is meant here in a broad sense, like, for instance, Jablonka and Lamb (2005), who include into it the epigenetic, genetic, behavioural, and symbolic inheritance. 
cells. I would still argue that some form of memory, not necessarily discrete symbol strings, is the source of all heritable information. Where would a semiotician say symbols are located when not in use?

$\boldsymbol{K}$. That's right. Where memory, of course, is not just a structure but a correspondence (i.e., a relation between structures) that is modified and conveyed in semiosis.

Thus biosemiotics is the field that not only tackles the mind-matter problem, but also addresses the problem of complementarity of semiotic and physical descriptions at all levels. There is a whole series of problems of the "symbol-matter" type that you have listed in your writings. Can you describe these?

$\boldsymbol{H}$. The amazing property of symbols is their ability to control the lawful behavior of matter, while the laws, on the other hand, do not exert control over the symbols or their coded references. It is just for this reason that evolution can construct endless varieties of species and the brain can learn and create endless varieties of models of the world. That is why organisms and symbol systems in some sense locally appear to escape the global behavior of physical laws, yet without ever disobeying them. Fully understanding this power of symbols over matter at all evolutionary levels is what I call "the symbol-matter problem".

The four most notorious symbol-matter levels are the genetic code in biology, pattern recognition and sensorimotor control in nervous systems, the measurement and control problem in physics, and the mind-body problem in philosophy.

$\boldsymbol{K}$. It occurs to me that any true model of semiosis has to include in itself the "symbol-matter problem" as you call it. The models of sign that don't include it may be useful in certain cases, but in order to be a model of semiosis, i.e. of sign process, the inclusion of symbol-matter problem is inescapable. 
$\boldsymbol{H}$. I think the "symbol-matter problem" is maybe not the best name because it is a triadic relation. The symbol and matter must be connected by an intepreter (Peirce's "system of interpretance"). Following the physicists" use of "cut" to separate the measurement from what is measured, I have also called the necessary separation of symbol and referent the "epistemic cut" which is also a triadic relation that must comprise the interpreter.

Both these phrases appear to evade the problem because symbol, matter, and cut are relatively simple to describe compared to what is necessary to describe for an actual measurement process or any system of interpretance. I have said, along with most biosemioticians, that the simplest system of interpretance is the living cell (Pattee 1969). I have also suggested that the enzyme constitutes the simplest functional measuring device (Pattee 1971b). Only if the enzyme recognizes (measures) its substrate by binding does it function as a specific catalyst. Furthermore, the relation between its substrate recognition and its catalytic function is not determined by laws but only by virtue of its genetic construction.

K. I think we need a special term to mark the connections or structures that are made specifically by semiosis, i.e. via a semiotic control. These are the pieces of semiosis "left behind", the fractions that are produced as parts of relations or codes, or of memory. In the cultural sphere, these are usually called 'artefacts', but as far as I know there is no general term for this in biology or in physics. ${ }^{6}$ These are the structures made when using the physical indeterminacy - like the proteins that are built by ribozymes, or the nests built by birds. Most of the living matter (as chemical structures) is such, and also what remains

6 Except a proposal made by M. Barbieri who proposes simply to extend the term 'artefact' over the everything made (or manufactured) by life. Another, but different approach is developed by J. Deely, who is extending the term 'object' to anything what is either recognised or produced; since, however, the objects are (as Deely argues) always a part of the action of signs, this leads him as a result to extend the semiosis to occur in the non-living world. 
after an organism has died, so most of the material in ecosystems belongs to this, because it is made via semiotic control.

What is interesting with these 'products of semiosis' - while these are often very different from the structures that appear without any semiotic control in the non-living world, these may also be indistinguishable from the latter. An oligopeptide produced by a cell may be indistinguishable from an oligopeptide which has formed by a stochastic condensation of aminoacids, likewise a replacement of some stones in a stony seashore may be indistinguishable from a replacement resulted by waves, or even $\mathrm{CO}_{2}$ synthesised by cells via respiration is as much $\mathrm{CO}_{2}$ as the one that comes from burning. The products of life in these examples are not just indistinguishable - these are the same as the ones that are not products of life.

The latter implies something important. Because if the humanmade artefacts are mostly well distinguishable from the things that are naturally formed in the non-living world, then due to the biosemiotically well-argued shift of semiotic threshold from the border of culture to the border of life, the distinction between the natural and life-made becomes structurally indistinguishable. In other words, what is made turns out to be both identical and non-identical to the things what are not made.

This is a very interesting case from the logical point of view, because on the one hand the distinction would need a term, but on the other hand, if we would introduce such a term, this would inevidently lead to a wish to define the qualitative difference - which is absent. Life is qualitatively different from non-life, but what it produces is both different and non-different.

How to solve this problem?

The solution would obviously require a more detailed description of the semiotic control.

The functional cycle (in Uexküll's sense) as a model of semiosis can be of some use here. It has always a double relation (recognition and action) to the object. This demonstrates well that from the side of recognition, the distinction is always qualitative, because the recognition of an object is controlled by memory. The results of an action 
(production, manufacturing), however, are not directly controlled the only way to control it will be again via a recognition. The action does some work - but this work may do almost everything. It may build, and it may destroy. In this sense, as the activities of life, even building and destroying turn out not to be basically different. Decomposition and synthesis are equally the parts of life's metabolism and activities, and these may become distinguishable only for some higher forms of life; both may need energy, both may need semiotic control; there is no principal difference at the level of enzymatic processes, whether the process is establishing or removing a chemical bond. Both may be exergonic or endergonic. Even the concept of negentropy does not make a difference here. Thus, indeed, life (the semiotic control) may influence almost any process in almost any way. Which means that knowing obviously always does more than it knows.

$\boldsymbol{H}$. You are right. There is no simple way to distinguish a molecule that is synthesized under semiotic control from exactly the same molecule arising spontaneously. I discussed this problem in a paper titled How does a molecule become a message in which I concluded,

A molecule does not become a message because of any particular shape or structure or behavior of the molecule. A molecule becomes a message only in the context of a larger system of physical constraints which I have called a 'language' in analogy to our normal usage of the concept of message. (Pattee 1969)

And as we agree, the simplest language or semiotic control process arises in the simplest self-replicating unit.

\section{The principles and discoveries}

$\boldsymbol{K}$. For me, there are two fundamental observations or discoveries or results - upon which the whole semiotic biology stands.

The first is the explanation for the biodiversity of species, and the variety of the types of categorizations. This is the answer to the 
question 'Why there are species in the living world?' To put it very briefly, the biosemiotic answer is that communication (biparental reproduction being a kind of communication) in the non-categorised set of individuals would not be stable (Kull 1992). In other words, this is to explain why communication creates discretizations.

The second is the plurality of objects in the semiosphere. A thing in the physical world is just one, whereas in the semiotic world it is always many, it just cannot be one until it has a meaning (Kull 2007). Semiosis makes the world plural. Like, for instance, a painting physically, it is a concrete pattern of pigments, but semiotically it is many things that can be recognised (or to what it refers).

From your point of view, what are the most important observations that motivated your interest in biosemiotics? And what are the important biosemiotic discoveries?

$\boldsymbol{H}$. Living systems have always been a challenge, even a threat, to physicists who believe their laws are universal in principle, but appear to be no help in explaining life. How do you explain why living systems are so clearly different from non living systems when they both obey exactly the same laws? That was the question that first motivated me. I first saw this question in Karl Pearson's Grammar of Science (1937: 287), a copy of which my Headmaster gave to me in the 8th grade. I still have the book and refer to it. Many physicists worried about this problem, like Erwin Schrödinger, Niels Bohr, and Max Delbrück who are well known for their writing on the subject. Linguists, on the other hand, are understandably not concerned about this problem.

\section{Roots and reminiscences}

K. Semiotic biology is polyphyletic - it has several roots. Even the term 'biosemiotics' has been coined independently couple of times.'

7 Probably Rothschild's (1962) and Stepanov's (1971) usage of the term 'biosemiotic' were independent. 
Contemporary biosemiotics includes scholars from different backgrounds and with different use of terminology, who after having recognized that their understandings match, accepted to build a shared conceptual apparatus, a common discourse.

The components of ideas that led me finally (in the end of 1980s) to biosemiotics, as I would reconstruct these now, include seemingly (a) my early and strong (and continuous) interest in theoretical biology (which led me to exchange a few letters with Conrad H. Waddington and Robert Rosen, in 1970s); (b) a strong semiotic (however, mainly cultural semiotic) school in Tartu; (c) contacts with biologists of non-neodarwinian views (on the one hand among Russian scholars, followers of the school of Lev Berg and Alexandr Lubischev, including the biologists of my own generation Sergey Chebanov and Alexei Sharov, and on the other hand the scholars carrying the tradition of Karl Ernst von Baer in Estonia); (d) my former participation in the research group of animal behaviour studies where I came across with Jakob von Uexküll's works (the search of his traces resulted in contacts with Thure von Uexküll, and via him with Thomas Sebeok); and certainly (e) the modelling research I carried out via which I understood the mechanism that is responsible for the emergence of species (which is very close to Hugh Paterson's recognition of the concept of species). After all this, and since the meeting with our Danish colleages Jesper Hoffmeyer and Claus Emmeche in early 1990s, biosemiotics remained the stable name for the work that followed.

Histories of life, of course, are always plural. What are the paths that led you to biosemiotics?

$\boldsymbol{H}$. Well, it was not only Pearson's question of why life is so different from nonliving systems when they both obey exactly the same laws. It was Pearson's idealistic view even about physical theory that replaced my naive realism in thinking about both physics and biology. He made me see how all of our models are based on epistemological assumptions and limited by our modes of thought. Einstein's epistemology was influenced by Pearson's Grammar. Heinrich Hertz expressed 
these limitations of our models in his Principles of Mechanics (Hertz 1956 [1894]: 1-2):

We form for ourselves images or symbols of external objects; and the form which we give them is such that the logically necessary consequents of the images in thought are always the images of the necessary consequents in nature of the things pictured.

[...] For our purpose it is not necessary that they [images] should be in conformity with the things in any other respect whatever. As a matter of fact, we do not know, nor have we any means of knowing, whether our conceptions of things are in conformity with them in any other than this one fundamental respect."

Besides Hertz's separation of the knower and the known, there was von Neumann's (1955: 419-420) discussion of measurement in which he shows why an epistemic cut between them is a conceptual necessity, although its placement is largely arbitrary. It was also von Neumann's (1966) logic of self-replication that made clear the necessity of symbolic description as distinct from material dynamics to allow an unlimited evolution of novelty.

I have acknowledged elsewhere (Pattee 2001) some of the other physicists, biologists, and philosophers that have influenced my thought.

$\boldsymbol{K}$. There are several approaches and scholars whom we can identify as biosemioticians but who themselves did not know or use that term. For instance, after reading Robert Rosen's (1991) Life itself, I realised that he had reached the biosemiotic understanding - his emphasis is on the triadic relation.

$\boldsymbol{H}$. There were indeed many physicists and biologists who, beginning in the 1950s, belonged to what Gunther Stent called the Information School of molecular biology (Stent 1968). It was generally recognized by this group that there was more to biology than just the molecular structures of DNA and proteins. Their focus on information clearly was a semiotic perspective. 
Rosen was not a part of this group, but his emphasis on "relational biology" depended on semiotic rather than material relations. Rosen and I were friends for many years beginning with our studies of hierarchy theory in the 1960s. To us, hierarchies, like measurement, are also dependent on semiotic distinctions because hierarchical levels are recognized by the necessity of different descriptions. We also focussed on epistemology. Rosen's modeling relation was based on Hertz's statement above (Pattee 2007).

\section{The way to proceed}

$\boldsymbol{K}$. A large part of the existing biosemiotic studies has been devoted to theoretical and philosophical questions. However, what should the semiotic approach mean for biological experiments and observations, what is its relationship to empirical studies? ${ }^{8}$

$\boldsymbol{H}$. I see this question as the central issue for biosemiotics. Earlier in our discussion you mentioned the "need for a special term" for structures arising from semiosis. This terminology problem is a symptom of a larger problem that biosemiotics is facing. It is already clear from our discussion that my physics language is different from your semiotic language; but the problem is deeper than language. Physics and semiotics have two very different cultures, and biochemistry is a third culture. The problem is even worse because all these areas have subcultures with their special foci and terminologies.

I'm sure you are aware of this culture problem. The two of us are both motivated to try to resolve our different language problem by discussions like this one. Unfortunately this is not the common motivation of most biochemists. When they are confronted with the biosemiotics perspective, they often resist semiotic expression of the problems of life as nothing but restatements of what they describe in

8 Some points on the role of biosemiotic empirical research are described in Kull, Emmeche, Favareau 2008. 
their well-developed material language, which they regard as a more scientific description of life.

It is not clear to me what biosemiotics wants to be. All I can suggest is that if its practitioners want it to be accepted as science rather than as philosophy, they must focus more on empirically decidable models, rather than emphasizing its linguistic and philosophical foundations. In other words, if biosemiotics claims that symbolic control is the distinguishing characteristic of life, and if it also claims to be a science, then it must clearly define symbols and codes in empirical scientific terms that are more familiar to physicists and molecular biologists.

On the other hand, if biosemiotics is not primarily the study of symbolic matter but the study of symbolic meaning, then as I have emphasized (Pattee 2008), this requires a different epistemological principle than does the study of physics and biology. It will also require a language more familiar to philosophers and linguists.

One must keep in mind that the biosemiotic concepts like symbol function and meaning arise only by natural or cultural selection from those constraint structures that physical laws do not determine; and yet all physical laws as well as all scientific models must be expressed in such symbol systems.

$K$. What should be the main biosemiotic questions in which the further research in biosemiotics should focus on? Can we give a brief list of these?

H. Again, it is not clear what the main contributions of biosemiotics will turn out to be. As we learn more about the complexity of genetic expression, the analogies of genetic memory and natural language may not carry beyond the fact that they both use discrete, linear strings from a small arbitrary alphabet. So far, we have found nothing in the network of neurons in the brain that interprets sentences anything like the cell interprets genes by the construction of proteins.

Molecular biology is currently totally involved with sophisticated technologies trying to unravel the functions and linkages in the masses of gene sequences data. These technologies already have specialized 
names like genomics, proteomics, and even transcriptomics. Even though all these studies could be correctly described as biosemiotics, I think it is very unlikely that the biosemiotic literature will alter the style or language of these highly competitive and incredibly complex empirical technologies.

In my opinion, biosemiotics will make the most lasting contribution by addressing the classical problems inherent in symbolic description and control of material systems at all levels - the symbolmatter problem. In this way it will contribute most to the epistemic foundations of all the sciences, of both the living and the nonliving.

$K$. The main reason why we are developing the biosemiotic concepts is obviously just our wish to understand why and how life works. Since the questions we are dealing with are quite fundamental and related to several central questions of biology, it will also mean a reformulation (or rebuilding) of theoretical biology in many of its parts. Much of it comes out as a consequence from the application of the models of semiosis. The biosemiotic improvement of models of semiosis would probably also influence the whole theory of semiotics, which in its turn has consequences for humanities and for the relationship between physical sciences and humanities. ${ }^{9}$

\section{References}

Eddington, Arthur Stanley 1929. The Nature of the Physical World. Cambridge: Cambridge University Press.

Elsasser, Walter M. 1998 [1987]. Reflections on a Theory of Organisms: Holism in Biology. Baltimore: The Johns Hopkins University Press.

Hertz, Heinrich 1956 [1894]. The Principles of Mechanics Presented in a New Form. Mineola: Dover Publications. [Jones, D. E.; Walley, J. T., trans.; Original German edition 1894, Die Principien der Mechanik in neuem Zusammenhange dargestellt, Leipzig.]

9 Acknowledgements: to Fulbright Scholarship Program, the European Regional Development Fund, Center of Excellence CECT, ETF6669 
Hoffmeyer, Jesper 2008. Biosemiotics: An Examination into the Signs of Life and the Life of Signs. Scranton: Scranton University Press.

Jablonka, Eva; Lamb, Marion J. 2005. Evolution in Four Dimensions: Genetic, Epigenetic, Behavioral, and Symbolic Variation in the History of Life. Cambridge: The MIT Press.

Kull, Kalevi 1992. Evolution and semiotics. In: Sebeok, Thomas A.; Umiker-Sebeok, Jean (eds.), Biosemiotics: Semiotic Web 1991. Berlin: Mouton de Gruyter, 221-233.

- 2007. Biosemiotics and biophysics - the fundamental approaches to the study of life. In: Barbieri, Marcello (ed.), Introduction to Biosemiotics: The New Biological Synthesis. Berlin: Springer, 167-177.

Kull, Kalevi; Emmeche, Claus; Favareau, Donald 2008. Biosemiotic questions. Biosemiotics 1(1): 41-55.

Neumann, John von 1955 [1932]. Mathematical Foundations of Quantum Mechanics. Princeton: Princeton University Press. [Beyer, Robert T., trans.]

- 1966. Theory of Self-Reproducing Automata. Urbana: University of Illinois Press. [Burks, Arthur W., ed.]

Pattee, Howard H. 1969. How does a molecule become a message? Developmental Biology Supplement 3: 1-16.

- Physical theories of biological coordination. Quarterly Reviews of Biophysics 4(2/3): 255-276.

- 1971b. Can life explain quantum mechanics? In: Bastin, Ted (ed.), Quantum Theory and Beyond - Essays and Discussions Arising from a Colloquium. London: Cambridge University Press, 307-319.

- 1988. Simulations, realizations, and theories of life. In: Langton, Christopher G. (ed.), Artificial Life. Reading: Addison-Wesley, 63-77.

- 2001. The physics of symbols: Bridging the epistemic cut. BioSystems 60: 5-21.

- 2007. Laws, constraints, and the modeling relation - history and interpretations. Chemistry and Biodiversity 4: 2272-2295.

- 2008. Physical and functional conditions for symbols, codes, and languages. Biosemiotics 1(2): 147-168.

Pearson, Karl 1937 [1892]. The Grammar of Science. London: J. M. Dent and Sons.

Polanyi, Michael 1968. Life's irreducible structure. Science 160: 1308-1312.

Rosen, Robert 1991. Life Itself. New York: Columbia University Press.

Rothschild, Friedrich S. 1962. Laws of symbolic mediation in the dynamics of self and personality. Annals of New York Academy of Sciences 96: 774-784.

Stent, Gunther 1968. That was the molecular biology that was. Science 169: 390395.

Stepanov, Yurij S. 1971. Semiotika. Moskva: Nauka. 


\section{Биосемиотическая беседа: между физикой и семиотикой}

В этом диалоге мы говорим о контрасте между непреложными законами физики и семиотической свободой жизни. Мы приходим к выводу, что необходимы дополнительные виды описания для материальных и символических структур, а также и для многих иерархических уровней этих структур. Далее дается разъяснение того, что мы имеем в виду под понятиями «законы», «ограничения», «правила», «символы», «память», «интерпретаторы» и «семиотический контроль». Кроме того, мы кратко характеризуем путь, который привел нас в биосемиотику, и размышляем о будущем биосемиотики.

\section{Biosemiootiline vestlus: füiusika ja semiootika vahel}

Käesolevas dialoogis räägime kontrastist vääramatute füüsikaseaduste ja elu semiootilise vabaduse vahel. Leiame, et on vaja komplementaarseid kirjeldusviise materiaalsete ja sümboolsete struktuuride, nagu ka nende struktuuride paljude hierarhiliste tasandite jaoks. Selgitame, mida peame silmas mõistete "seadused", "piirangud", "reeglid", "sümbolid”, “mälu”, "tõlgendajad" ja "semiootiline kontroll” all. Peale selle kirjeldame lühidalt isiklikke taustu, mis meid kumbagi biosemiootika juurde tõi, ja spekuleerime biosemiootika tulevikusuundade üle. 